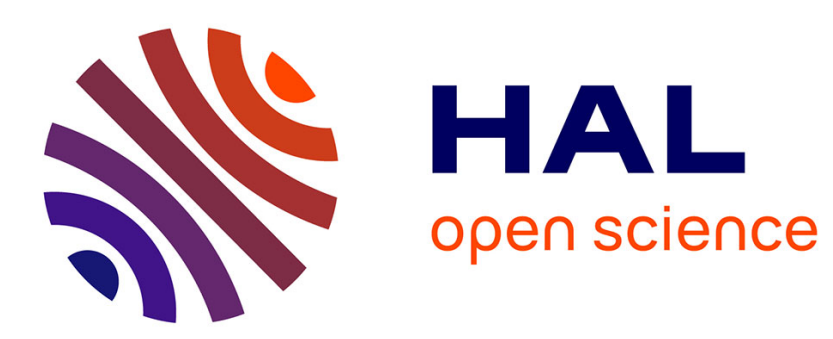

\title{
Non Linear Analytical Calculation of Magnetic Field and Torque of Switched Reluctance Machines
}

\author{
K.Z. Djelloul, Kamel Boughrara, Rachid Ibtiouen, Frédéric Dubas
}

\section{To cite this version:}

K.Z. Djelloul, Kamel Boughrara, Rachid Ibtiouen, Frédéric Dubas. Non Linear Analytical Calculation of Magnetic Field and Torque of Switched Reluctance Machines. International Conference on Electrical Sciences and Technologies in Maghreb, Oct 2016, Marrakech, Morocco. hal-02380280

\section{HAL Id: hal-02380280 \\ https://hal.science/hal-02380280}

Submitted on 26 Nov 2019

HAL is a multi-disciplinary open access archive for the deposit and dissemination of scientific research documents, whether they are published or not. The documents may come from teaching and research institutions in France or abroad, or from public or private research centers.
L'archive ouverte pluridisciplinaire HAL, est destinée au dépôt et à la diffusion de documents scientifiques de niveau recherche, publiés ou non, émanant des établissements d'enseignement et de recherche français ou étrangers, des laboratoires publics ou privés. 


\section{NonLinear Analytical Calculation of Magnetic Field and Torque of Switched Reluctance Machines}

\author{
K.Z. Djelloul \\ Laboratoire de l'Energie et des Systèmes Intelligents (LESI) \\ Université de Khemis-Miliana \\ Route de Theniet El-had, Khemis-Miliana, 44225, Algeria \\ zakaryadoc@hotamil.com
}

\author{
K. Boughrara ${ }^{1}$, R. Ibtiouen ${ }^{1}$, and F. Dubas ${ }^{2}$ \\ ${ }^{1}$ Laboratoire de Recherche en Electrotechnique (LRE) \\ Ecole Nationale Polytechnique (ENP Alger) \\ Algiers, 10, av. Pasteur, El Harrach, BP182, 16200, Algeria \\ ${ }^{2}$ ENERGY Department, FEMTO-ST Institute, UMR \\ CNRS 6174, UBFC, Belfort, France
}

\begin{abstract}
The paper deals with the nonlinear analytical harmonic modeling (HM) of 3-phases, and 6-slots/4-poles switched reluctance machine (SRM). The proposed model consists in computing magnetic field distribution and static torque of a conventional winding distribution SRM. Because a SRM has inherently nonlinear characteristics, the analytical subdomain model which does not take into account the saturation has a limited accuracy; this is due to the assumption of infinite tooth permeability. The new analytical subdomain model based on the HM technique, favorable to beyond this limitation, is presented with the consideration of the local magnetic saturation on the teeth. The results obtained with the nonlinear analytical model (NAM) are compared with the analytical subdomain model (without the saturation effect) and nonlinear finite elements method solutions.
\end{abstract}

Keywords-Harmonic modeling; subdomain method; magnetic field; electromagnetic performances; finite elements method; switched reluctance machine.

\section{INTRODUCTION}

SRMs have attracted increasing attention of electrical machine researchers and industrials due to their simplicity, robust performance, capable of handling high temperatures, reduction in the cost of power electronics devices and low cost maintenance as well as high torque density [1]-[7]. They have been successfully applied in electric vehicles, aircraft, mining machinery, autonomous generator,... [8]-[9]. Besides the previous advantages, some of their drawbacks are also evident such as high torque ripple and high acoustic noise. In order to decrease the noise emission and the vibration, many studies have been performed and some methods have been proposed [10]-[14]. Because a SRM has inherently nonlinear magnetic characteristics and a doubly salient pole structure, a finite element method (FEM) is often adopted to obtain accurate magnetic field distribution. However, the solution time can be large if the mesh is detailed and/or many simulations are required. For rapid solution, some analytical models of SRM were presented in [15]-[19]. In those papers, the ferromagnetic materials are considered with infinity permeability and/or only aligned position is considered.

In this paper, which takes the solution of magnetic field in the slots/teeth into account [20]-[21], a NonLinear Aanalytical Method (NAM) based on the subdomain Harmonic Model technique is presented. The developed model allows predicting the magnetic field distribution in the aligned and unaligned rotor position and the static electromagnetic torque in multiphase SRM with considering the nonlinear ferromagnetic characteristic. All results obtained with the NAM are then compared to those found by subdomain analytical model (AN) with the assumption of infinite tooth permeability and the nonlinear FEM [22].

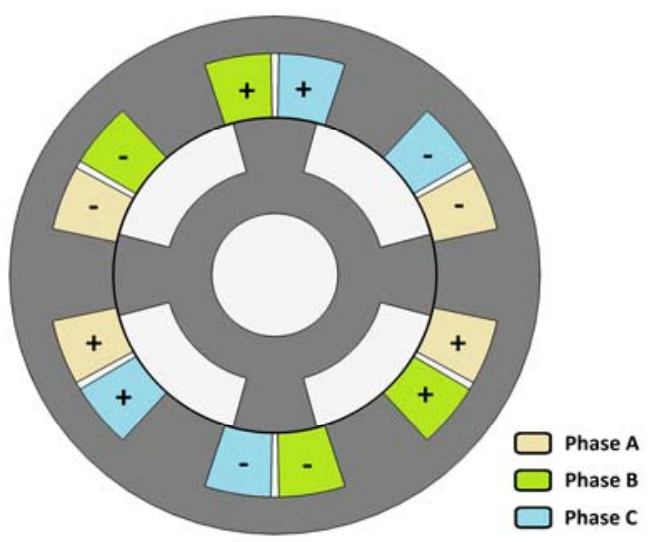

Fig. 1. Studied 6/4 SRM.

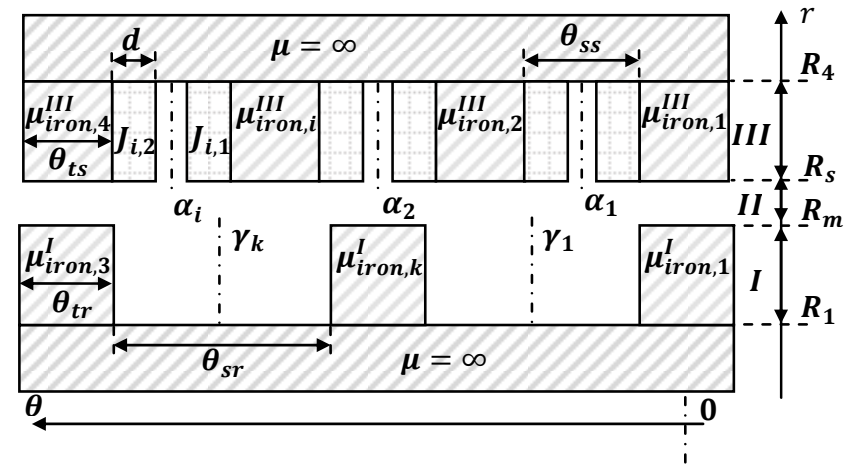

Fig. 2. Simplified model of SRM.

\section{Motor GeOMEtry AND Assumptions}

The geometric representation of a 3-phases, and 6-slots/4poles conventional winding distribution SRM is shown in Fig. 1 and 2. In the Fig. 2, Region I represents the rotor slots/teeth, Region II the air-gap and Region III stator 
slots/teeth. The angular position of the $i^{\text {th }}$ stator slot-opening and $k^{\text {th }}$ rotor slot-opening are defined respectively by

$$
\begin{gathered}
\alpha_{i}=\frac{2 \pi}{Q_{s}} i-\frac{\pi}{Q_{s}} \\
\gamma_{k}=\frac{2 \pi}{Q_{r}} k-\frac{\pi}{Q_{r}}+\phi
\end{gathered}
$$

with $1 \leq i \leq Q_{s}, 1 \leq k \leq Q_{r}$, and $\phi$ the position of the rotor.

The model is formulated in 2-D polar coordinate system with the following assumptions:

- Eddy current effects are neglected.

- The current density has only one component along the $z$-axis.

- The stator and rotor slots/teeth have radial sides.

- The axial length of the machine is considered infinite and invariant, end effects are neglected.

- The magnetic permeability in the stator and rotor (slots/teeth) is invariant in the radial direction, and variant in the tangential direction.

- The cores of the outer and inner part of the stator and rotor respectively are assumed infinitely permeable, for simplification.

\section{ARMAture CURRENT DENSITY AND PERMEABILITY SLOTS/TEETH DiSTRIBUTION}

\section{A. Stator Current Density Source}

The stator slot contains two coils as shown in Fig. 2. The current density $\vec{J}$ and the complex Fourier series expansion $J_{Z}(\theta)$ of this current density is given by

$$
\begin{gathered}
\vec{J}=J_{z}(\theta) \vec{e}_{z} \\
J_{z}(\theta)=\sum_{n=-N}^{N} \hat{J}_{z, n} e^{-j n \theta}
\end{gathered}
$$

with $(j)^{2}=-1$

The complex Fourier coefficients of $\hat{J}_{z, n}$ are calculated as

$$
\begin{aligned}
\hat{J}_{z, n}=\sum_{i=1}^{Q s} \frac{1}{2 \pi j n}\left[J_{i, 1} e^{-j n \frac{\theta_{S S}}{2}}\left(e^{j n d}-1\right)\right. \\
\left.+J_{i, 2} e^{j n \frac{\theta_{S S}}{2}}\left(1-e^{-j n d}\right)\right] e^{j n \alpha_{i}}
\end{aligned}
$$

where the stator current densities in the slots for double layer armature winding are defined as

$$
\begin{aligned}
& J_{i, 1}=\frac{N_{c}}{S} C_{(1)}^{T}\left[\begin{array}{lll}
I_{a} & I_{b} & I_{c}
\end{array}\right] \\
& J_{i, 2}=\frac{N_{c}}{S} C_{(2)}^{T}\left[\begin{array}{lll}
I_{a} & I_{b} & I_{c}
\end{array}\right]
\end{aligned}
$$

where $S=\mathrm{d}\left(R_{4}^{2}-R_{S}^{2}\right) / 2$ is the surface of the stator slot coil, and $C_{(1)}^{T} \& C_{(2)}^{T}$ are the transpose of the connecting matrix between the 3-phases current and the stator slots, that represent the distribution of stator windings in the slots of the 6/4 SRM with double layer winding is given by

$$
\begin{aligned}
C_{(1)} & =\left[\begin{array}{rrrrrr}
-1 & 0 & 0 & 1 & 0 & 0 \\
0 & 1 & 0 & 0 & -1 & 0 \\
0 & 0 & -1 & 0 & 0 & 1
\end{array}\right] \\
C_{(2)} & =\left[\begin{array}{rrrrrr}
0 & 0 & -1 & 0 & 0 & 1 \\
-1 & 0 & 0 & 1 & 0 & 0 \\
0 & 1 & 0 & 0 & -1 & 0
\end{array}\right]
\end{aligned}
$$

\section{B. Stator and Rotor Permeability Distribution}

For the slots/teeth in the rotor (i.e., Region I) and stator (i.e., Region III) of 6/4 SRM, the representation of permeability is given by

$$
\begin{gathered}
\mu(\theta)=\sum_{n=-N}^{N} \hat{\mu}_{n} e^{-j n \theta} \\
\mu^{r e c}(\theta)=\sum_{n=-N}^{N} \hat{\mu}_{n}^{r e c} e^{-j n \theta}
\end{gathered}
$$

The coefficients of $\hat{\mu}_{n}$ and $\hat{\mu}_{n}^{\text {rec }}$ for the Region I and III, given in the Appendix, are calculated with the distribution of permeability defined as following

$$
\begin{aligned}
& \mu^{I I I}(\theta)= \begin{cases}\mu_{0}, & \theta \in\left[\alpha_{i}-\frac{\theta_{s s}}{2}, \alpha_{i}+\frac{\theta_{s s}}{2}\right] \\
\mu_{\text {iron }, i}^{I I I}, & \theta \in\left[\alpha_{i}-\frac{\theta_{s s}}{2}-\theta_{t s}, \alpha_{i}-\frac{\theta_{s s}}{2}[\right.\end{cases} \\
& \mu^{I}(\theta)= \begin{cases}\mu_{0}, & \theta \in\left[\gamma_{k}-\frac{\theta_{s r}}{2}, \gamma_{k}+\frac{\theta_{s r}}{2}[\right. \\
\mu_{\text {iron }, k}^{I}, & \theta \in\left[\gamma_{k}-\frac{\theta_{s r}}{2}-\theta_{t r}, \gamma_{k}-\frac{\theta_{s r}}{2}[\right.\end{cases}
\end{aligned}
$$

where $\theta_{t s}=\left(2 \pi / Q_{s}\right)-\theta_{s s} \& \theta_{t r}=\left(2 \pi / Q_{r}\right)-\theta_{s r} \quad$ are respectively the stator and rotor tooth opening.

The field vectors $\vec{B}$ and $\vec{H}$ are coupled by

$$
\vec{B}=\mu \vec{H}
$$

In the case, that the magnetic permeability is invariant in the tangential direction, (14) becomes $\vec{B}_{r}=\mu \vec{H}_{r}$ and $\vec{B}_{\theta}=\mu \vec{H}_{\theta}$. In our case, the magnetic permeability is variant in the tangential direction, (14) is given by [23]

$$
\begin{aligned}
& \vec{B}_{r}=\mu_{c r} \vec{H}_{r} \\
& \vec{B}_{\theta}=\mu_{c \theta} \vec{H}_{\theta}
\end{aligned}
$$

where $\mu_{c r}$ and $\mu_{c \theta}$ are respectively the radial and tangential magnetic permeability. 
By using the complex Fourier and the Cauchy's product theorem in (15) and (16), explained in more detail in [20], the coefficients constitutive relation of $\mu_{c r}$ and $\mu_{c \theta}$ are given by

$$
\begin{gathered}
\hat{\mu}_{n, c r}=\sum_{n=-N}^{N} \sum_{n^{\prime}=-N}^{N} \hat{\mu}_{n-n^{\prime}} \\
\hat{\mu}_{n, c \theta}=\left[\sum_{n=-N}^{N} \sum_{n^{\prime}=-N}^{N} \hat{\mu}_{n-n^{\prime}}^{r e c}\right]^{-1}
\end{gathered}
$$

The permeability convolution matrices for the radial and the tangential of these coefficients of (17) and (18) is given by

$$
\begin{gathered}
\boldsymbol{\mu}_{c, r}=\left[\begin{array}{ccc}
\hat{\mu}_{0} & \cdots & \hat{\mu}_{-2 N} \\
\vdots & \ddots & \vdots \\
\hat{\mu}_{2 N} & \cdots & \hat{\mu}_{0}
\end{array}\right] \\
\boldsymbol{\mu}_{c, \theta}=\left(\boldsymbol{\mu}_{c, \theta}^{r e c}\right)^{-1}=\left[\begin{array}{ccc}
\hat{\mu}_{0}^{r e c} & \cdots & \hat{\mu}_{-2 N}^{r e c} \\
\vdots & \ddots & \vdots \\
\hat{\mu}_{2 N}^{r e c} & \cdots & \hat{\mu}_{0}^{r e c}
\end{array}\right]^{-1}
\end{gathered}
$$

\section{MAGNETIC FIELD IN 6/4 SRM}

By using the complex Fourier series decomposition and the method of separation of variables in $r$ and $\theta$, we can find the solution to Poisson's and Laplace's equation in all regions, for that, all coefficient $\hat{A}_{z, n}$ of the vector potential $\vec{A}$ is gathering in one column vectors $\mathbf{A}_{z}$.

\section{A. Armature Slots/Teeth (Region III)}

Magnetic field calculation in the stator slots with double layer winding and teeth region is calculated with solving the following Poisson's matrix equations

$$
\frac{\partial^{2} \mathbf{A}_{z}^{I I I}}{\partial r^{2}}+\frac{1}{r} \frac{\partial \mathbf{A}_{z}^{I I I}}{\partial r}-\frac{1}{r^{2}} \mathbf{V}^{I I I} \mathbf{A}_{z}^{I I I}=-\boldsymbol{\mu}_{c, \theta}^{I I I} \mathbf{J}_{\mathbf{z}}
$$

where $\mathbf{V}^{I I I}=\boldsymbol{\mu}_{c, \theta}^{I I I} \mathbf{N}_{\theta}\left(\boldsymbol{\mu}_{c, r}^{I I I}\right)^{-1} \mathbf{N}_{\theta}$, and $\mathbf{N}_{\theta}$ is the diagonal matrix of $n$, given by

$$
\mathbf{N}_{\theta}=\left[\begin{array}{ccc}
-N & \cdots & 0 \\
\vdots & \ddots & \vdots \\
0 & \cdots & N
\end{array}\right]
$$

The expression for the general solution of (21) is formulated as

$$
\mathbf{A}_{z}^{I I I}=\mathbf{W}^{I I I}\left(\frac{r}{R_{4}}\right)^{\lambda^{I I I}} \mathbf{a}^{I I I}+\mathbf{W}^{I I I}\left(\frac{R_{s}}{r}\right)^{\lambda^{I I I}} \mathbf{b}^{I I I}+r^{2} \mathbf{F}
$$

where $\lambda^{I I I}$ and $\mathbf{W}^{I I I}$ are respectively the diagonal eigenvalue and the eigenvector matrix of $\left(\mathbf{V}^{I I I}\right)^{\frac{1}{2}}, \mathbf{a}^{I I I} \& \mathbf{b}^{I I I}$ are the column vectors of the constants unknown coefficients, and the term $r^{2} \mathbf{F}$ represented the particular solution of (21) with $\mathbf{F}$ given by

$$
\mathbf{F}=\left(\mathbf{V}^{I I I}-4 \mathbf{I}\right)^{-1} \boldsymbol{\mu}_{c, \theta}^{I I I} \mathbf{J}_{\mathbf{z}}
$$

where $\mathbf{I}$ is a diagonal identity matrix with same size as $\mathbf{N}_{\theta}$, and $\mathbf{J}_{\mathrm{z}}$ is the column vectors of the all coefficients $\hat{J}_{z, n}$.

\section{B. Rotor Slots/Teeth (Region I)}

The Laplace matrix equation in the rotor slots/teeth, which is an annular domain delimited by the radii $R_{m}$ and $R_{1}$, is given by

$$
\frac{\partial^{2} \mathbf{A}_{z}^{I}}{\partial r^{2}}+\frac{1}{r} \frac{\partial \mathbf{A}_{z}^{I}}{\partial r}-\frac{1}{r^{2}} \mathbf{V}^{I} \mathbf{A}_{z}^{I}=0
$$

where $\mathbf{V}^{I}=\boldsymbol{\mu}_{c, \theta}^{I} \mathbf{N}_{\theta}\left(\boldsymbol{\mu}_{c, r}^{I}\right)^{-1} \mathbf{N}_{\theta}$.

The general solution can be obtained directly from (23) with $\mathbf{F}=0$

$$
\mathbf{A}_{z}^{I}=\mathbf{W}^{I}\left(\frac{r}{R_{m}}\right)^{\lambda^{I}} \mathbf{a}^{I}+\mathbf{W}^{I}\left(\frac{R_{1}}{r}\right)^{\lambda^{I}} \mathbf{b}^{I}
$$

where $\lambda^{I}$ and $\mathbf{W}^{I}$ are respectively the diagonal eigenvalue and the eigenvector matrix of $\left(\mathbf{V}^{I}\right)^{\frac{1}{2}}$.

C. Air-Gap (Region II)

In the air-gap region, we have to solve Laplace's matrix equation

$$
\frac{\partial^{2} \mathbf{A}_{z}^{I I}}{\partial r^{2}}+\frac{1}{r} \frac{\partial \mathbf{A}_{z}^{I I}}{\partial r}-\left(\frac{\mathbf{N}_{\theta}}{r}\right)^{2} \mathbf{A}_{z}^{I I}=0
$$

The general solution of (27) can be written as

$$
\mathbf{A}_{z}^{I I}=\left(\frac{r}{R_{s}}\right)^{\lambda^{I I}} \mathbf{a}^{I I}+\left(\frac{R_{m}}{r}\right)^{\lambda^{I I}} \mathbf{b}^{I I}
$$

where $\lambda^{I I}=\sqrt{\left(\mathbf{N}_{\theta}\right)^{2}}=\left|\mathbf{N}_{\theta}\right|$.

The matrix equation of field $\left\{\mathbf{B}_{r} ; \mathbf{B}_{\theta}\right\}$ and $\left\{\mathbf{H}_{r} ; \mathbf{H}_{\theta}\right\}$ in the different regions are given by

$$
\begin{aligned}
& \mathbf{B}_{r}=\frac{1}{r} \frac{\partial \mathbf{A}_{z}}{\partial \theta}=-j \frac{1}{r} \mathbf{N}_{\theta} \mathbf{A}_{z} \\
& \mathbf{B}_{\theta}=-\frac{\partial \mathbf{A}_{z}}{\partial r} \\
& \mathbf{H}_{r}=-j \frac{1}{r} \boldsymbol{\mu}_{c, r}^{-1} \mathbf{N}_{\theta} \mathbf{A}_{z}
\end{aligned}
$$




$$
\mathbf{H}_{\theta}=-\boldsymbol{\mu}_{c, \theta}^{-1} \frac{\partial \mathbf{A}_{z}}{\partial r}
$$

\section{Interfaces Conditions}

The studied SRM [see Fig. 2] is constituted with three regions, there are two interface continuous boundary conditions at $R_{m} \& R_{s}$, and the application of the conditions Neumann boundary to the inner (outer) boundary of Region I (Region III) with infinitely permeable material is assumed, given by as

$$
\begin{aligned}
& \mathbf{A}_{z}^{I I}-\left.\mathbf{A}_{z}^{I}\right|_{r=R_{m}}=0 \\
& \mathbf{A}_{z}^{I I I}-\left.\mathbf{A}_{z}^{I I}\right|_{r=R_{s}}=0 \\
& \mathbf{H}_{\theta}^{I I}-\left.\mathbf{H}_{\theta}^{I}\right|_{r=R_{m}}=0 \\
& \mathbf{H}_{\theta}^{I I}-\left.\mathbf{H}_{\theta}^{I I}\right|_{r=R_{S}}=0 \\
& \left.\mathbf{H}_{\theta}^{I}\right|_{r=R_{1}}=0 \\
& \left.\mathbf{H}_{\theta}^{I I}\right|_{r=R_{4}}=0
\end{aligned}
$$

The system of six boundary conditions matrix equations (33) to (38) permits to determine the coefficients of the vector potentials in the three regions of 6/4 SRM.

\section{ALGORITHM For NONLINEAR SOLVING}

The magnetic saturation effects are calculated only in the stator and rotor teeth of the SRM. The back iron has been chosen in order to amplify a bit this effects are shown in Fig. 3, with the characteristic $\mu_{r}(B)$ [see Fig. 3(b)] which is obtained directly by $\mu_{r}=B /\left(H \mu_{0}\right)$ form the curve $B(H)$ [see Fig. 3(a)].

The algorithm presented in Fig. $\mathbf{5}$ is used to estimate the level of saturation in the SRM by an iterative procedure, with $\xi$ is the maximum allowable error to achieve convergence of solution, if the error less than $\xi$, the analysis is finished. The update permeability values is assured by the algorithm shown in Fig. 4, in first step the relative permeability equal the maximum value given by the curve $\mu_{r}(B)$, the next update determined through by the difference between $\mu_{r}$ and $\mu_{r, \text { test }}$ in all teeth one by one, is by adding half the previous value either a positive or negative value only in the case that the error greater than $\xi$.

\section{Vi. Electromagnetic Torque Calculation}

According to Maxwell stress tensor method, electromagnetic torque $T_{e m}$ is computed by

$$
T_{e m}=\frac{L_{u} R_{g}^{2}}{\mu_{0}} \int_{0}^{2 \pi} B_{r}^{I I}\left(R_{g}, \theta\right) B_{\theta}^{I I}\left(R_{g}, \theta\right) d \theta
$$

where $R_{g}$ is the radius of a circle placed at the middle of the air-gap, and $L_{u}$ the axial length of the motor.

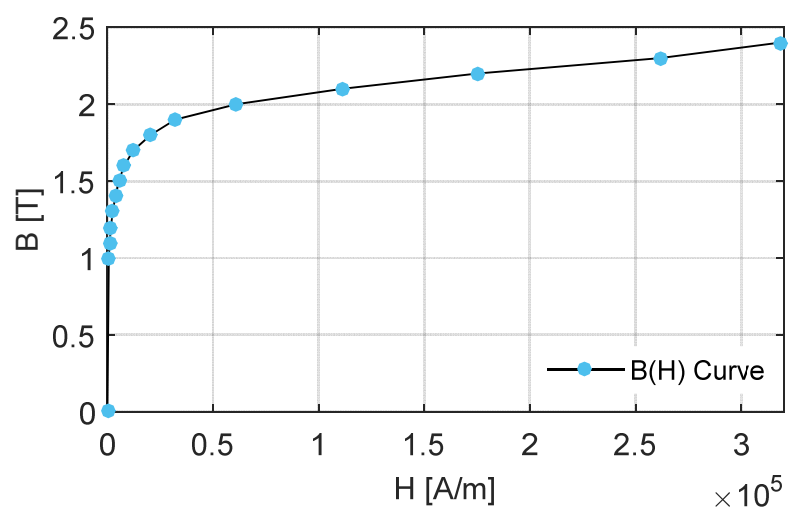

(a)

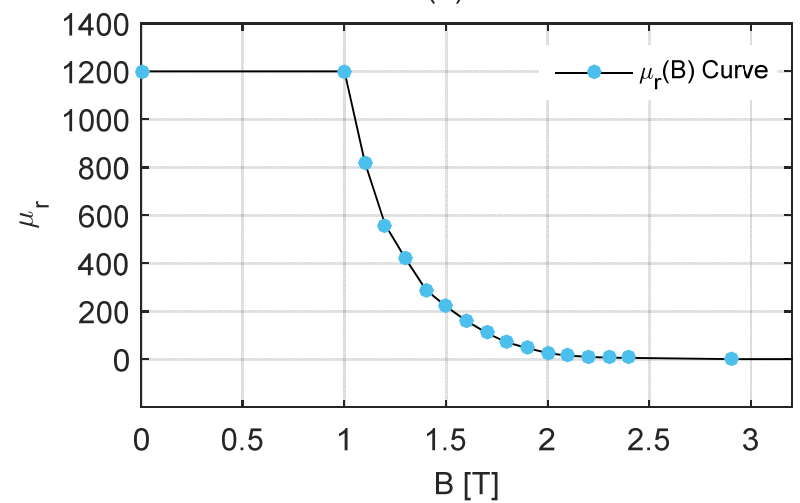

(b)

Fig. 3. Characteristic of the stator/rotor back iron used in nonlinear analytical/FEM simulation: (a) $B(H)$ and (b) $\mu_{r}(B)$.

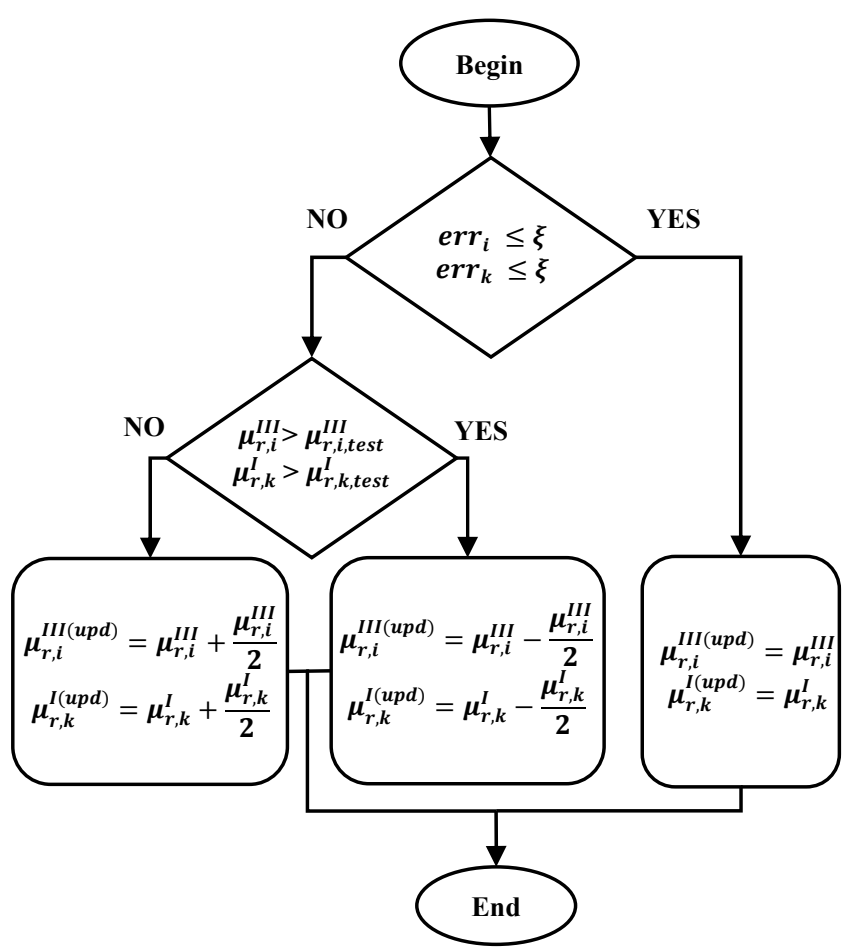

Fig. 4. Organigramme for update step relative permeability values. 


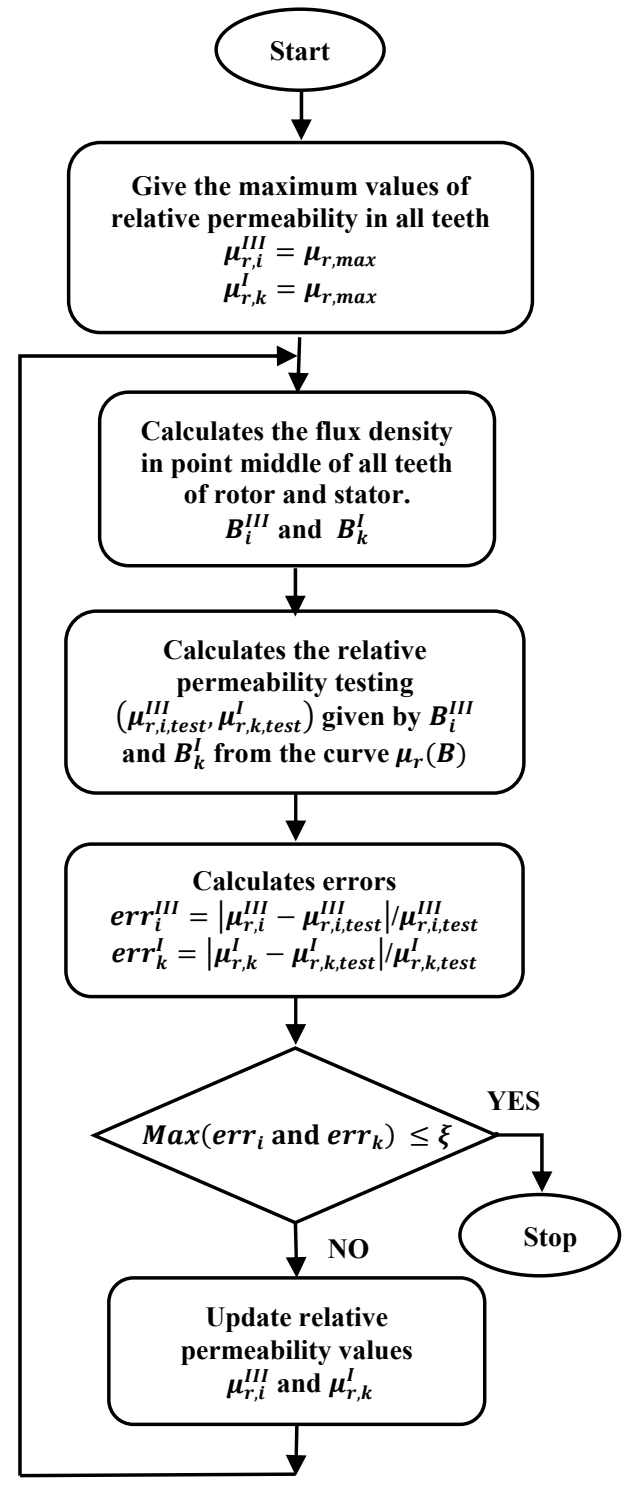

Fig. 5. Organigramme for estimation of the saturation level.

\section{RESULTS AND VALIDATION}

The NAM is used to determine the magnetic field distribution and the electromagnetic performances of a $6 / 4$ SRM. The main dimensions and parameters of the studied machine are given in Table I. The NAM results are verified by nonlinear FEM, and compared with the solutions of linear AM. The description of AM without the saturation effect of a SRM can be found in [18].

The magnetic field distribution is done for one phase fed by a constant current with a current density per coil equal to $3 \mathrm{~A} / \mathrm{mm}^{2}$ in aligned and unaligned position corresponds to $\phi=0^{\circ}$ and $45^{\circ}$ rototation of rotor position respectivly. Figs. 6 and $\mathbf{8}$ show the relative permeability distrubition in the stator and rotor slots/teeth of 6/4 SRM. Figs. 7 and 9 show a comparison between analytical, nonlinear analytical and FEM radial and tangential flux densities of 6/4 SRM.
TABLE I. PARAMETERS OF 6/4 SRM.

\begin{tabular}{|l|l|l|}
\hline SумвОL & \multicolumn{1}{|c|}{ Parameter } & Value and unit \\
\hline$Q_{s}$ & Number of stator slots & 6 \\
$Q_{r}$ & Number of rotor poles & 4 \\
$R_{1}$ & Internal radius of rotor slot & $17.3 \mathrm{~mm}$ \\
$R_{4}$ & External radius of stator slot & $36 \mathrm{~mm}$ \\
$R_{\text {ext }}$ & Radius of the external stator surface & $45 \mathrm{~mm}$ \\
$R_{s}$ & Radius of the stator internal surface & $25.7 \mathrm{~mm}$ \\
$R_{m}$ & Radius of the rotor surface & $25.5 \mathrm{~mm}$ \\
$g$ & Air-gap length & $0.2 \mathrm{~mm}$ \\
$L_{u}$ & Stack length & $60 \mathrm{~mm}$ \\
$R_{i}$ & Radius of the shaft & $10 \mathrm{~mm}$ \\
$\theta_{s r}$ & Rotor slot opening & $60^{\circ}$ \\
$\theta_{s s}$ & Stator slot opening & $36^{\circ}$ \\
$d$ & Opening of a slot coil & $17^{\circ}$ \\
$I$ & Phase current & $15 \mathrm{~A}$ \\
$N_{c}$ & Number of conductor of slot coil & 20 \\
\hline
\end{tabular}

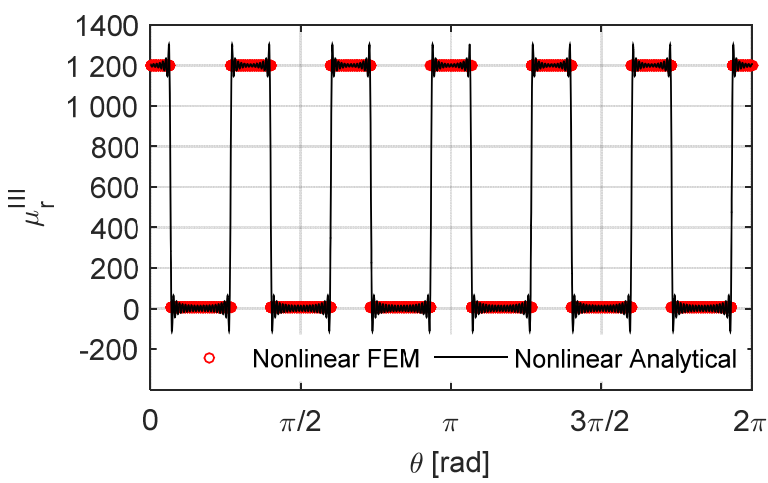

(a)

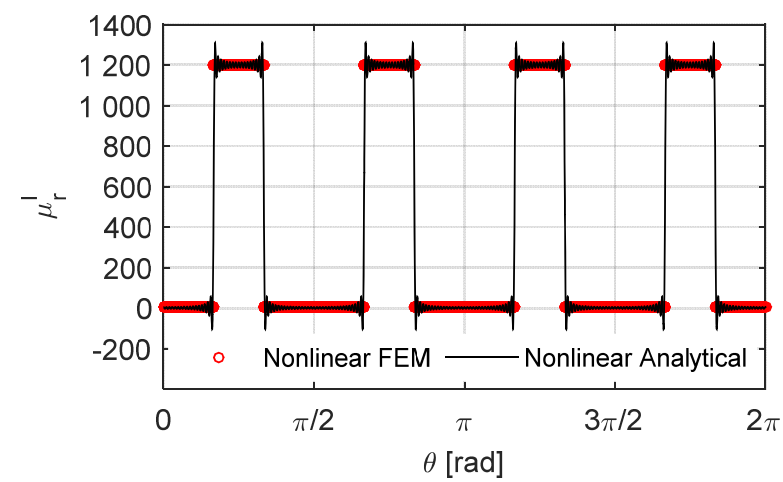

(b)

Fig. 6. Relative permeability distribution due to phase A in the unaligned position in the middle of: (a) Region I, and (b) Region III. 


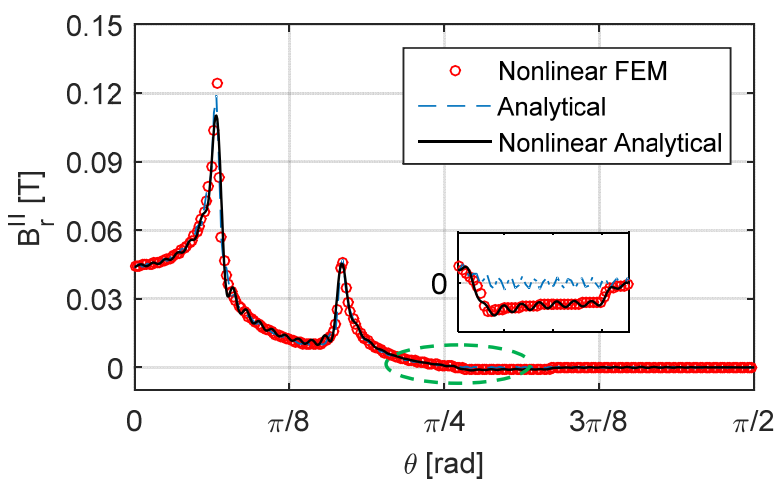

(a)

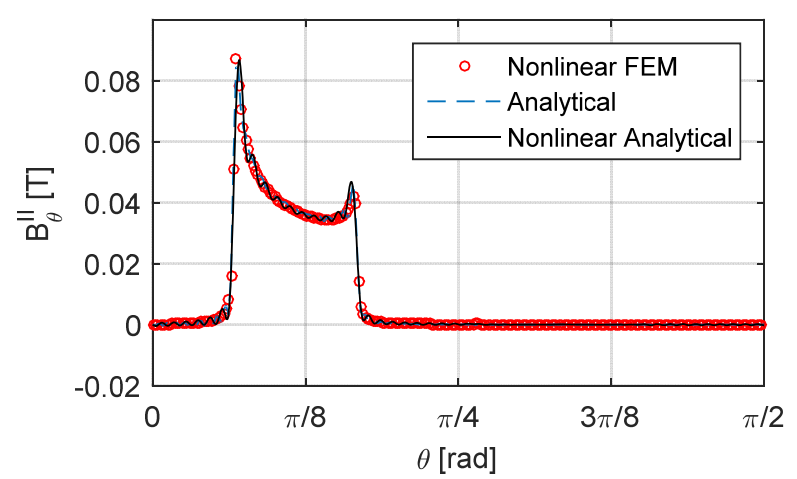

(b)

Fig. 7. Flux density due to phase $\mathrm{A}$ in the unaligned position: (a) radial, and (b) tangential.

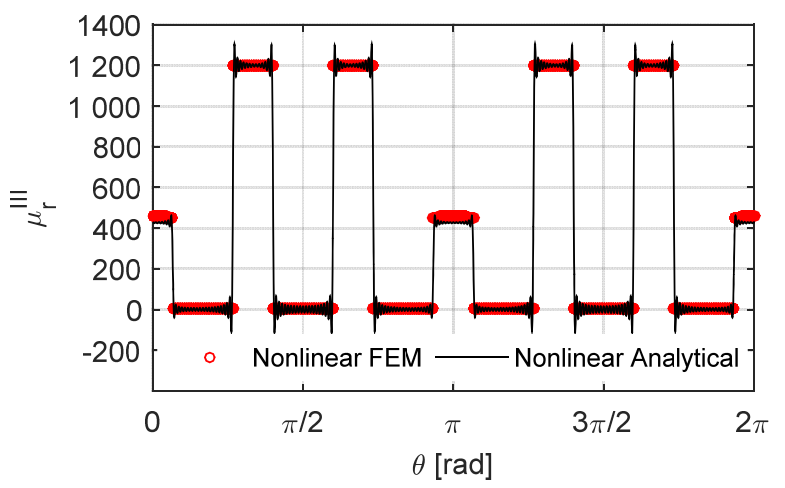

(a)

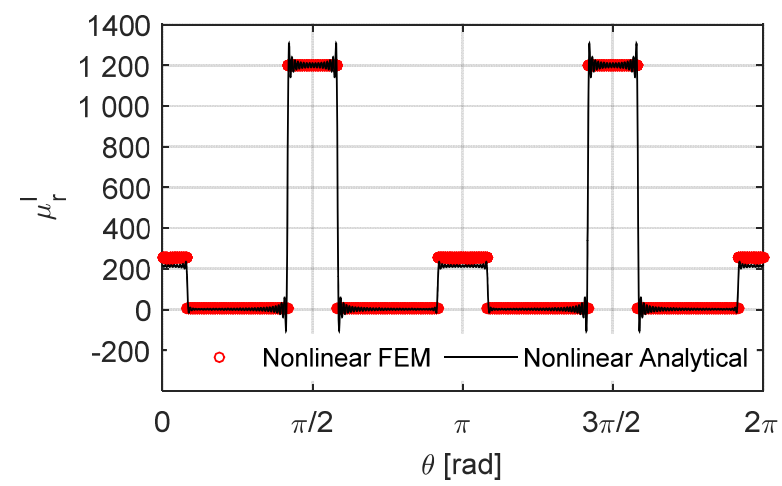

(b)

Fig. 8. Relative permeability distrubition due to phase $\mathrm{A}$ in the aligned position in the middle of: (a) Region I, and (b) Region III.

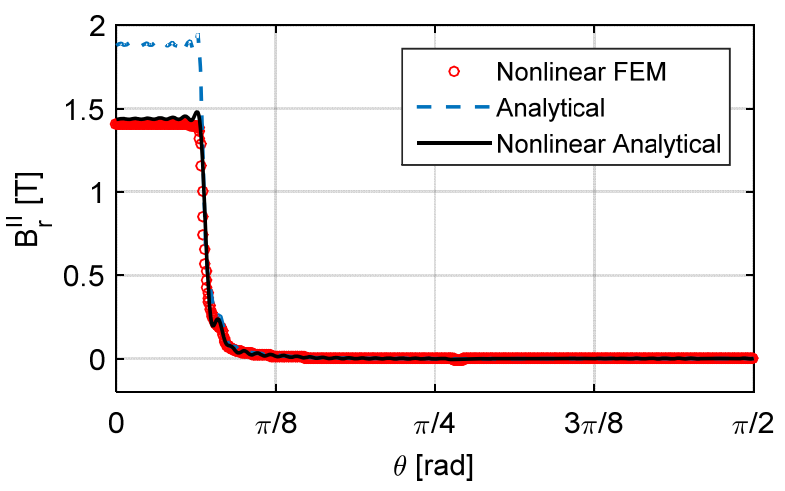

(a)

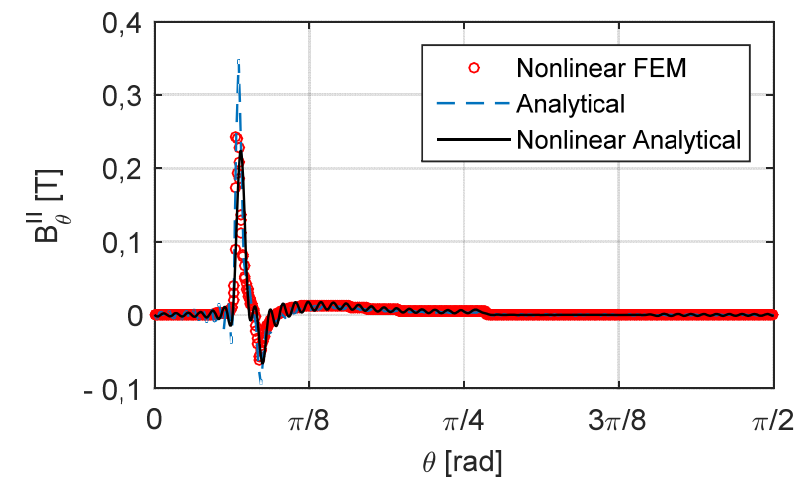

(b)

Fig. 9. Flux density due to phase A in the aligned position: (a) radial, and (b) tangential.

In the unaligned position where the flux density in the iron is situated in the linear part of the curve $B(H)$, is confirmed by Fig. 6, the relative permeability vary between $\mu_{r}=1$ in slots and $\mu_{r, \operatorname{Max}}=1200$ in all teeth. The results of NAM is very accurate and in excellent agreement with FEM [see Fig. 7], which confirm the accuracy of this model for magnetic field prediction. However, by comparised between analytical solution and the other solution in the zoom zone [see Fig. 7(a)], we find little difference, as a magnetic short circuit exists, following to the presence of a convergence between some of the stator and rotor teeth, is gives zero magnetic field in the airgap, due to the permeability in AM are assumed to be infinitely $(\mu=\infty)$ in the iron, but the NAM take the solution of this problem into account.

In the aligned position, the effect of nonlinear magnetic characteristic is important for the current density of $3 \mathrm{~A} / \mathrm{mm}^{2}$ confirmed by Fig. 9, the estimation of the saturation level is obtained with the relative permeability in $1^{\text {st }}$ and $3^{\text {nd }}$ tooth of rotor pole stay in 225 for nonlinear analytical and 250 for nonlinear FEM, and in $1^{\text {st }}$ and $4^{\text {nd }}$ tooth of stator stay in 430 and 455 for nonlinear analytical and FEM respectivly, in other teeth stay in the linear part with $\mu_{r, \operatorname{Max}}=1200$.

The results shown in Fig. 9, note that the nonlinear analytical and FEM study results are in very good agreement. In Fig. 9(a), the radial flux density obtained with nonlinear analytical and FEM is lower to the values obtained by AM, the NAM is very accurate and in excellent agreement with 


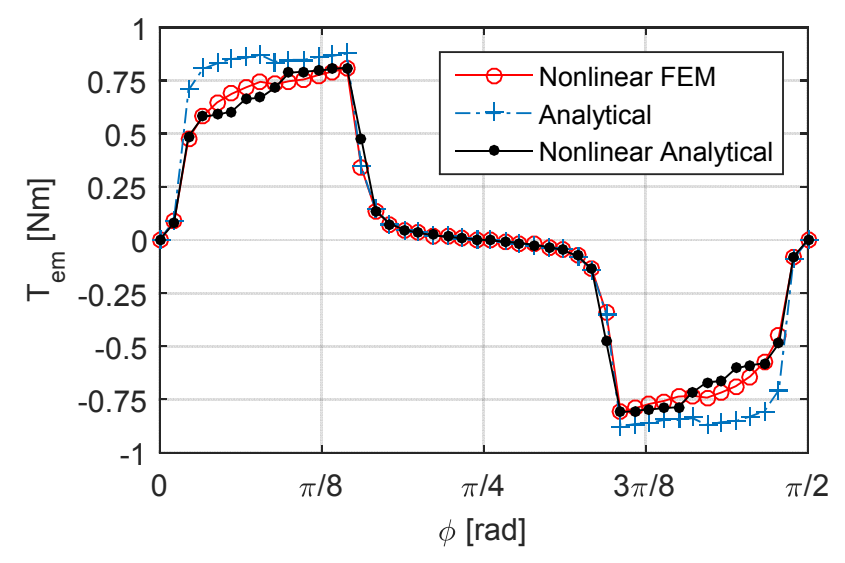

Fig. 10. Static electromagnetic torque due to phase A.

nonlinear FEM is confirmed than NAM beyond the limitation of AM.

For the conventional type of winding distribution SRM, in Fig. 10, the static electromagnetic torque due to phase A given by the nonlinear analytical agree very well with nonlinear FEM, on the other side, in the result of the AM a considerable difference in amplitude between this model and other models can be shown especialy when the position of rotor is aproaching the aligned position. The NAM is accurate for this type of machine in aligned and unaligned position.

\section{CONCLUSION}

In this paper, we have proposed an accurate Nonlinear Analytical subdomain Model (NAM) for predicting the magnetic field distribution in any rotor position and the static electromagnetic torque in multiphase SRM. The developed model takes into account the effect of the magnetic saturation by introducing iteratively the curve $B(H)$ of the soft magnetic material. Because the conventional winding distribution SRM presents a nonlinear characteristic, the linear analytical subdomain method (AM) is not accurate compared to NAM. Therefore, the proposed analytical model is considered as a viable to FEM for analysis of SRM.

\section{APPENDIX}

The coefficients of $\hat{\mu}_{n}$ and $\hat{\mu}_{n}^{r e c}$ for the Region I and III is given by

$$
\hat{\mu}_{n}^{I I I}= \begin{cases}\sum_{i=1}^{Q s} \frac{1}{2 \pi j n}\left[\mu_{\text {iron }, i}^{I I I} e^{-j n \frac{\theta_{s s}}{2}}\left(1-e^{-j n \theta_{t s}}\right)\right. & n \neq 0 \\ \left.\quad+2 j \mu_{0} \sin \left(\frac{n \theta_{s s}}{2}\right)\right] e^{j n \alpha_{i}} & n=0 \\ \sum_{i=1}^{Q s} \frac{1}{2 \pi}\left(\mu_{\text {iron }, i}^{I I I} \theta_{t s}+\mu_{0} \theta_{s s}\right) & \end{cases}
$$

$$
\hat{\mu}_{n}^{I I r e c}=\left\{\begin{array}{cc}
\sum_{i=1}^{Q s} \frac{1}{2 \pi j n}\left[\frac{1}{\mu_{\text {iron }, i}^{I I I}} e^{-j n \frac{\theta_{S S}}{2}}\left(1-e^{-j n \theta_{t s}}\right)\right. \\
\left.\quad+\frac{2 j}{\mu_{0}} \sin \left(\frac{n \theta_{s s}}{2}\right)\right] e^{j n \alpha_{i}} & n \neq 0 \\
\sum_{i=1}^{Q s} \frac{1}{2 \pi}\left(\frac{1}{\mu_{\text {iron }, i}^{I I I}} \theta_{t s}+\frac{1}{\mu_{0}} \theta_{s s}\right) & n=0
\end{array}\right.
$$

$\hat{\mu}_{n}^{I}= \begin{cases}\sum_{k=1}^{Q r} \frac{1}{2 \pi j n}\left[\mu_{\text {iron }, k}^{I} e^{-j n \frac{\theta_{s r}}{2}}\left(1-e^{-j n \theta_{t r}}\right)\right. & n \neq 0 \\ \left.\quad+2 j \mu_{0} \sin \left(\frac{n \theta_{s r}}{2}\right)\right] e^{j n \gamma_{k}} & n=0 \\ \sum_{k=1}^{Q r} \frac{1}{2 \pi}\left(\mu_{\text {iron }, k}^{I} \theta_{t r}+\mu_{0} \theta_{s r}\right) & \end{cases}$

$$
\hat{\mu}_{n}^{I r e c}=\left\{\begin{array}{cc}
\sum_{k=1}^{Q r} \frac{1}{2 \pi j n}\left[\frac{1}{\mu_{\text {iron }, k}^{I}} e^{-j n \frac{\theta_{s r}}{2}}\left(1-e^{-j n \theta_{t r}}\right)\right. \\
\left.\quad+\frac{2 j}{\mu_{0}} \sin \left(\frac{n \theta_{s r}}{2}\right)\right] e^{j n \gamma_{k}} & n \neq 0 \\
\sum_{k=1}^{Q r} \frac{1}{2 \pi}\left(\frac{1}{\mu_{\text {iron }, k}^{I}} \theta_{t r}+\frac{1}{\mu_{0}} \theta_{s r}\right) & n=0
\end{array}\right.
$$

\section{REFERENCES}

[1] M. Takeno, A. Chiba, N. Hoshi, S. Ogasawara, M. Takemoto and A. Rahman "Test Results and Torque Improvement of the 50-kW Switched Reluctance Motor Designed for Hybrid Electric Vehicles", IEEE Trans. Industry Applications, vol. 48, No. 4, pp. 1327-1334, Jul.-Aug. 2012.

[2] M. Michon, S. Calverley and K. Atallah "Operating Strategies of Switched Reluctance Machines for Exhaust Gas Energy Recovery Systems", IEEE Trans. Industry Applications, vol. 48, No. 5, pp. 14781486, Sep.-Oct. 2012.

[3] A. Chiba and Y. Takano, M. Takeno, T. Imakawa, N. Hoshi, M. Takemoto and S. Ogasawara "Torque Density and Efficiency Improvements of a Switched Reluctance Motor Without Rare-Earth Material for Hybrid Vehicles", IEEE Trans. Industry Applications, vol. 47, No. 3, pp. 1240-1246, May.-Jun. 2011.

[4] G. J. Li, X. Ojeda, S. Hlioui, E. Hoang, M. Gabsi and C. Balpe "Comparative Study of Switched Reluctance Motors Performances for Two Current Distributions and Excitation Modes", Industrial Electronics Annual Conference (IECON'09), pp. 4047-4052, 2009.

[5] G. J. Li, J. Ojeda, E. Hoang, M. Lecrivain and M. Gabsi "Comparative Studies of Between Classical and Mutually Coupled Switched Reluctance Motors Using Thermal-Electromagnetic Analysis for Driving Cycles", IEEE Trans. Magnetics, vol. 47, No. 4, pp. 839-847, Apr. 2011.

[6] G. J. Li, J. Ojeda, S. Hlioui, E. Hoang, M. Lecrivain and M. Gabsi "Modification in Rotor Pole Geometry of Mutually Coupled Switched Reluctance Machine for Torque Ripple Mitigating", IEEE Trans. Magnetics., vol. 48, No. 6, pp. 2025-2034, Jun. 2012.

[7] J. W. Ahn, H. K. M. Khoi, and D.H. Lee, "Design and Analysis of High Speed 4/2 SRMs for an air-blower", IEEE International Symposium on Industrial Electronics (ISIE), pp. 1242-1246, 2010.

[8] N. Radimov, N. Ben-Hail, and R. Rabinovici, "Switched reluctance machines as three-phase AC autonomous generator", IEEE Trans. Magnetics, vol. 42, No. 11, pp. 3760-3764, Nov. 2006. 
[9] H. Cheng, H. Chen, and Z. Yang, "Design indicators and structure optimisation of switched reluctance machine for electric vehicles", IET Electric Power Applications, vol. 9, no 4, pp. 319-331, 2015.

[10] C. Sahin, A. E. Amac, M. Karacor, and A. Emadi, "Reducing torque ripple of switched reluctance machines by relocation of rotor moulding clinches“, IET Electric Power Applications, vol. 6, no. 9, pp. 753-760, 2012.

[11] M. N. Anwar and O. Husain, "Radial force calculation and acoustic noise prediction in switched reluctance machines", IEEE Trans. Industry Applications, vol. 36, No 6, pp. 1589-1597, Nov.-Dec. 2000.

[12] C. Lin and B. Fahimi, "Prediction of Acoustic Noise in Switched Reluctance Motor Drives", IEEE Trans. on Energy Conversion, vol. 29, No 1, pp. 250-258, Mar. 2014.

[13] S. A. Long, Z. Q. Zhu, and D. Howe, "Effectiveness of active noise and vibration cancellation for switched reluctance machines operating under alternative control strategies", IEEE Trans. on Energy Conversion, vol. 20, No 4, pp. 792-801, Dec. 2005.

[14] Z. Q. Zhu, X. Liu, and Z. Pan, "Analytical Model for Predicting Maximum Reduction Levels of Vibration and Noise in Switched Reluctance Machine by Active Vibration Cancellation”, IEEE Trans. on Energy Conversion, vol. 26, No 1, pp. 36-45, Mar 2011.

[15] A. Kechroud, J. H. Paulides and E. A. Lomonova "B-Spline Neural Network to Inverse Problems in Switched Reluctance Motor Optimal Design”, IEEE Trans. Magnetics, vol. 47, No. 10, pp. 4179-4182, Oct. 2011.

[16] A. Radun “Analytical Calculation of the Switched Reluctance Motor's Unaligned Inductance", IEEE Trans. Magnetics, vol. 35, No. 6, pp. 4473-4481, Nov. 1999.
[17] S. H. Mao, D. Dorrell and M. C. Tsai "Fast Analytical Determination of Aligned and Unaligned Flux Linkage in Switched Reluctance Motors Based on a Magnetic Circuit Model", IEEE Trans. Magnetics, vol. 45, No. 7, pp. 2935-2942, Jul. 2009.

[18] K. Boughrara, T. Lubin, and R. Ibtiouen, "General Subdomain Model for Predicting Magnetic Field in Internal and External Rotor Multiphase Flux-Switching Machines Topologies“, IEEE Trans. on Magnetics, vol. 49, No 10, pp. 5310-5325, Oct. 2013.

[19] B. Schinnerl and D. Gerling, "Novel Analytical Calculation Method for the Non-Linear $\Psi$-I-Characteristic of Switched Reluctance Machines in the Aligned Rotor Position",IEEE International Electric Machines and Drives Conference (IEMDC), Antalya, Turkey, 2006.

[20] R. L. J. Sprangers, J. J. H. Paulides, B. L. J. Gysen, and E. A. Lomonova "Magnetic Saturation in Semi-Analytical Harmonic Modeling for Electric Machine Analysis", IEEE Trans. Magnetics, vol. 52, No. 2, Feb. 2016, Art. ID 8100410

[21] R. L. J. Sprangers, J. J. H. Paulides, B. L. J. Gysen, J. Waarma, and E. A. Lomonova, "Semi-analytical framework for synchronous reluctance motor analysis including finite soft-magnetic material permeability," IEEE Trans. Magnetics, vol. 51, no. 11, Nov. 2015, Art. ID 8110504.

[22] D. C. Meeker, Finite Element Method Magnetics. ver. 4.2 (1 Apr. 2009 Build) [Online]. Available: http://www.femm.info

[23] G. Madescu, I. Boldea, and T. J. E. Miller, "An analytical iterative model (AIM) for induction motor design," in Proc. Conf. Rec. IEEEIAS Annual. Meeting, vol. 1. San Diego, CA, USA, Oct. 1996, pp. 566573. 